ovarian metastases of breast cancer were found in 40 patients $(23,5 \%)$. Multivariate analyses revealed that younger ages (OR, $0.94 ; 95 \% \mathrm{CI}, 0.88$ to $0.99 ; \mathrm{p}=0.04$ ) and the number of sites of metastasis at surgery ( $\geq 3$ sites; OR, 3.99; 95\% CI, 1.37 to $11.59 ; \mathrm{p}=0.01)$ were significantly related with breast cancer ovarian metastases. The remaining studied characteristics were not statistically significant.

Conclusions Younger ages and having 3 or more sites of metastases at surgery appears to be risk factors for ovarian implants in previously metastatic breast cancer patients.

\section{EPV024/\#508 ADENOID CYSTIC CARCINOMA OF THE BREAST IN MEXICAN POPULATION: EXPERIENCE OF 12 YEARS A CENTER OF CONCENTRATION}

${ }^{1} \mathrm{G}$ Moreno*, ${ }^{2} \mathrm{DA}$ Maciel Roman, ${ }^{2} \mathrm{~V}$ Bautista Pina, ${ }^{2} \mathrm{JA}$ Tenorio Torres, ${ }^{2} \mathrm{~F}$ Villegas Carlos. ${ }^{1}$ National Cancer Institute, Mexico, Gynecology Oncology, Tlalpan, Mexico; ${ }^{2}$ Breast Disease Institute, Surgery, Coyoacán, Mexico

\subsection{6/ijgc-2021-IGCS.91}

Objectives Describe the presentation characteristics of ACC in the Mexican population at the Breast Disease Institute from 2007 to 2019.

Methods Observational, descriptive, case series, of Breast Disease Institute FUCAM ${ }^{\circledR}$ patients.

Results A case series was recorded with 9 patients with ACC (table 1), representing $0.5 \%$ of our breast cancer cases. With an average age of presentation of 63 years. Grade III was presented in $66.6 \%$. The mean tumor size was $4.8 \mathrm{~cm}$, while the mean tumor size in the surgical specimen was $2.5 \mathrm{~cm}$, in $88.8 \%$ in early stages. All with triple negative breast cancer (TNBC) (table 2), one case (5\%) with lymph node involvement with Axillary lymph node dissection (ALND). In a case of Breast conserving surgery (BCS) with Intraoperative radiation therapy (IORT) with Intrabem, two cases with modified radical mastectomy (MRM), 66\% with total mastectomy (MT) and sentinel node biopsy (SLNB). In 55\% of the cases, adjuvant chemotherapy taxane-based. While $44.4 \%$ were indicated radiotherapy, with an average disease-free period of 63 months.

Conclusions So we consider that our contribution can answer some questions of ACC in the population Mexican. We present our 12-year institutional experience with 9 cases. Our

\begin{tabular}{|c|c|c|c|c|c|c|c|c|}
\hline \multicolumn{9}{|c|}{ Table I: Characteristics of patients } \\
\hline Case & $\begin{array}{l}\text { Age at } \\
\text { Diagnosis } \\
\text { (years) }\end{array}$ & Histology & Grade & Pattern & $\begin{array}{l}\text { cT } \\
(\mathrm{cm})\end{array}$ & pT $(\mathbf{c m})$ & $\begin{array}{l}\text { Clinical } \\
\text { stage } \\
\text { AJCC }\end{array}$ & $\begin{array}{l}\text { Pathological } \\
\text { stage } \\
\text { AJCC }\end{array}$ \\
\hline 1 & 43 & $\mathrm{ACC}$ & III & Basaloid & 9 & 5.1 & $\mathrm{IIB}(\mathrm{T} 3)$ & $\| \mathrm{B}$ \\
\hline 2 & 49 & $\mathrm{ACC}$ & III & Cribiform & 11 & 1.1 & IA & IA \\
\hline 3 & 72 & ACC & 1 & Cribiform & 2.8 & 2.3 & $\| \mathrm{A}$ & $\| \mathrm{A}$ \\
\hline 4 & 51 & $\mathrm{ACC}$ & 1 & 0 & 2 & 3.5 & $\| \mathrm{A}$ & $\| A$ \\
\hline 5 & 72 & $\mathrm{ACC}+\mathrm{DClS}$ & III & Multifocal & 2 & 1.7 & $\| B$ & $\| \mathrm{A}$ \\
\hline 6 & 77 & ACC & 1 & Invasive & 2 & 3 & $\| \mathrm{A}$ & $\| A$ \\
\hline 7 & 60 & ACC & III & Invasive & 1.5 & 1 & IB & IB \\
\hline 8 & 56 & ACC & III & Cribiform & 3.5 & 3 & $\| \mathrm{A}$ & $\| \mathrm{A}$ \\
\hline 9 & 60 & $\mathrm{ACC}$ & III & Invasive & 3 & 3 & $\| \mathrm{A}$ & $\| \mathrm{A}$ \\
\hline Mean & 63 & & & & 4.8 & 2.5 & & \\
\hline
\end{tabular}

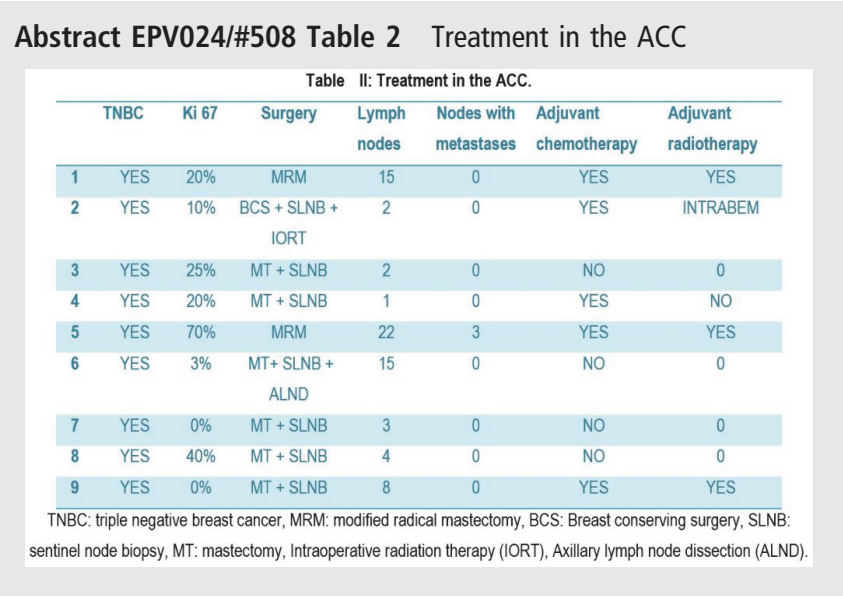

results are similar to the published series, however there is controversy for treatment with adjuvant.

\section{EPV025/\#546 CLINICAL-PATHOLOGICAL FEATURES AND TREATMENT MODALITIES IN DCIS WITH MICROINVASION: A TUNISIAN EXPERIENCE}

${ }^{1} S$ Slim*, ${ }^{2} \mathrm{H}$ Bouaziz, ${ }^{3} \mathrm{R}$ Ben Romdhane, ${ }^{3} \mathrm{I}$ Marghli, ${ }^{4} \mathrm{~S}$ Kammoun, ${ }^{5} \mathrm{M}$ Driss, ${ }^{2} \mathrm{R}$ Chargui, ${ }^{6} \mathrm{~K}$ Rahal. ${ }^{1}$ Salah Azaiez Institut of Oncology, Tunis, Surgical Oncology, Tunis, Tunisia; ${ }^{2}$ Salah Azaiez Institute of Oncology, Surgical Oncology, Tunis, Tunisia; ${ }^{3}$ Salah Azaiez Institut of Oncology, Tunis, Surgical Oncology Department, Tunis, Tunisia; ${ }^{4}$ Salah Azaiez Institute of Oncology, Department of Pathology, Tunis, Tunisia; ${ }^{5}$ Salah Azaiez Institute, Surgical Oncology, Monastir, Tunisia; ${ }^{6}$ Salah Azaiez Institute of Cancerology, Surgical Oncology, Tunis, Tunisia

\subsection{6/ijgc-2021-IGCS.92}

Objectives Ductal carcinoma in situ with microinvasion (DCISM) is rare, $<1 \%$ of all breast cancer cases. The histological definition of this entity remains controversial. Due to the inconsistent definition and limited data regarding this breast cancer subtype, there are no clear treatment recommendations.

Methods We retrospectively reviewed the clinical-pathological aspects, the treatments, and followed by a cohort of 17 patients diagnosed with DCISM and microinvasive carcinoma from 2000 to 2017 in our institution.

Results The median age was 52 years old, $58.8 \%$ of patients were menopausal, all patients were operated on, $42.2 \%$ had conservative treatment, sentinel lymph node dissection was performed in $64.7 \%$ of cases with no micro or macro-metastases. Pathological examination found DCISM in $47 \%$ of cases (53\% of cases were pure microinvasive ductal carcinoma). Comedonecrosis was found in only two cases. Hormonal receptors were positives in $87.9 \%$ of DCISM cases. We performed radiotherapy in $47 \%$ of patients. Adjuvant chemotherapy was prescribed to $17.6 \%$ of patients, and $70.6 \%$ of patients underwent adjuvant endocrine therapy. Only one case underwent targeted adjuvant therapy. The Median follow-up was 42 months. We did not notice any relapse or metastasis.

Conclusions The development of screening programs increases the diagnosis of small tumors, especially DCISM. This entity remains with a good prognosis. Better knowledge and evaluation of risk factors of relapse are needed to define adjuvant treatment. 